\title{
Wczesny wiek menarche - związek ze statusem społeczno-ekonomicznym oraz wybranymi czynnikami związanymi ze stanem zdrowia
}

\section{Early age at menarche - relationship with socioeconomic status and selected factors connected with health status}

\author{
Karolina Olszewska1', Katarzyna Kliś, Iwona Teul², Iwona Wronka \\ 'Zakład Antropologii Instytutu Zoologii Uniwersytetu Jagiellońskiego \\ ul. Gronostajowa 9, 30-387 Kraków \\ Kierownik: dr hab. Henryk Gtąb \\ ${ }^{2}$ Katedra i Zakład Anatomii Prawidłowej i Topograficznej Pomorskiego Uniwersytetu Medycznego w Szczecinie \\ al. Powstańców Wlkp. 72, 70-111 Szczecin \\ Kierownik: dr hab. n. med. Zbigniew Ziętek
}

\begin{abstract}
SUMMARY
Introduction: Current research from around the world indicates a trend toward younger ages at the first menstruation. At the same time more and more studies point out the negative consequences of early puberty. Early age at menarche is significantly correlated with the risk of metabolic syndrome, breast cancer and female reproductive system cancer, as well as illnesses such asthma and bulimia.

The aim of the study was to examine the relationship between age at menarche and socioeconomic status and selected factors connected with biological conditions.

Material and methods: The data were obtained from 671 female university students. Height, weight, waist and hip circumference were measured, and BMI, WHR, WHtR were calculated. A questionnaire form was used to assess the age at menarche,
\end{abstract}

biological conditions and socioeconomic status of the surveyed students.

Results: There were no significant differences in the number of the early, average and late maturing students between the socioeconomic groups. The early maturing girls were characterized by higher values of waist circumference, BMI, WHR and WHtR. The prevalence of obesity and abdominal obesity was highest among the early maturing girls. The analysis did not show statistically significant relationships between age at menarche and selected factors connected with biological conditions.

Conclusion: Early maturation increases the risk of obesity and central adiposity distribution.

Key words: early puberty, living conditions, biological condition.

\section{STRESZCZENIE}

Wstęp: Obecnie notuje się coraz wcześniejszy wiek wystąpienia pierwszej menstruacji, równocześnie coraz częściej zwraca się uwagę na negatywne skutki wczesnego dojrzewania. Wczesne dojrzewanie jest silnie związane z ryzykiem wystąpienia otyłości, zespołu metabolicznego, raka piersi i nowotworów układu rozrodczego, a także chorób, takich jak astma czy bulimia.

Celem pracy było zbadanie zależności pomiędzy wiekiem menarche a statusem społeczno-ekonomicznym oraz wybranymi czynnikami związanymi z kondycja biologiczną.

Materiał i metody: Dane zebrano od 671 studentek. U wszystkich badanych osób zmierzono masę i wysokość ciała, obwód pasa, obwód bioder oraz obliczono wskaźniki BMI, WHR i WHtR W ankiecie studentki odpowiadały na pytania dotyczące wieku menarche, aktualnej kondycji zdrowotnej oraz statusu społeczno-ekonomicznego.
Wyniki: Nie zaobserwowano istotnych statystycznie różnic pod względem liczby osób dojrzewających wcześnie, przeciętnie i późno w zależności od czynników społeczno-ekonomicznych. Dziewczęta wcześnie dojrzewające charakteryzują wyższe wartości obwodu pasa oraz BMI, WHR i WHtR niż dziewczęta dojrzewające przeciętnie i późno. Częstość występowania otyłości oraz otyłości brzusznej jest najwyższa w grupie dziewcząt wcześnie dojrzewających. Analizując związek tempa dojrzewania z wybranymi elementami związanymi z kondycją biologiczną, nie stwierdzono statystycznie istotnych zależności.

Wnioski: Wczesne dojrzewanie zwiększa ryzyko otyłości i centralnego rozmieszczenia tkanki tłuszczowej.

Słowa kluczowe: wczesne dojrzewanie, warunki życia, kondycja biologiczna.

\section{WSTĘP}

Obecnie notuje się coraz wcześniejszy wiek wystąpienia pierwszej menstruacji. Akceleracja dojrzewania obserwowana jest przede wszystkim w społeczeństwach, w których nastąpił wyraźny postęp cywilizacyjny i polepszenie warunków życia $[1,2,3]$. Na podstawie wyników wielu badań wykazano także, że dziewczęta pochodzące z rodzin o wyższym 
statusie społeczno-ekonomicznym dojrzewają wcześniej niż ich rówieśniczki z rodzin o statusie niższym [4]. W związku z tymi obserwacjami przyjęto uważać, że wczesne dojrzewanie jest wyrazem „dobrobytu społeczeństwa”. Należy się jednak zastanowić, czy jest to cecha korzystna dla organizmu. Z biologicznego i medycznego punktu widzenia trudno to ocenić i niewykluczone jest, że prawidłowy rozwój organizmu powinien następować $\mathrm{w}$ wolniejszym tempie [4].

Coraz częściej naukowcy zwracają uwagę na negatywne skutki wczesnego dojrzewania. Ma ono istotny wpływ na przebieg procesu wzrastania, a w konsekwencji na budowę somatyczną. Wczesne dojrzewania wiąże się najczęściej z niższą wysokością ciała, ale większym otłuszczeniem w wieku dorosłym [5, 6]. Dziewczęta, u których pierwsza miesiączka wystąpiła w młodszym wieku, mają dłuższy tułów, krótsze kończyny dolne oraz głębszą i szerszą klatkę piersiową. Wykazano przewagę endomorficznej budowy ciała dziewcząt wcześnie dojrzewających nad ektomorficzną u późno dojrzewających [7]. Udowodniono silne powiązanie wczesnego dojrzewania z otyłością. Dzieci wcześniej dojrzewające częściej mają problemy z otyłością niż dzieci dojrzewające w normie $[8,9,10]$. Wczesny wiek menarche zwiększa ryzyko nowotworu piersi $[11,12]$ czy chorób układu krążenia [13, 14]. U dziewcząt wcześnie dojrzewających stwierdzono także zwiększoną podatność na schorzenia układu oddechowego oraz alergie [15].

Celem pracy było zbadanie zależności pomiędzy wybranymi czynnikami a wiekiem menarche studentek. Sprawdzono:

- czy tempo dojrzewania jest zależne od czynników społeczno-ekonomicznych,

- czy dziewczęta wcześnie dojrzewające różnią się od przeciętnie dojrzewających pod względem wymiarów ciała,

- czy wczesne dojrzewanie sprzyja występowaniu otyłości oraz otyłości brzusznej,

- czy wczesne dojrzewanie zwiększa podatność na występowanie chorób alergicznych oraz chorób wirusowych lub bakteryjnych górnych dróg oddechowych.

\section{MATERIA $~ I$ METODY}

Podstawę pracy stanowiły dane zebrane od 671 studentek w przedziale wiekowym 18-25 lat. U wszystkich badanych osób zmierzono masę i wysokość ciała, obwód pasa, obwód bioder oraz obliczono następujące wskaźniki: BMI (wskaźnik masy ciała), WHR (waist to hip ratio) i WHtR (waist to height ratio). W ankiecie studentki odpowiadały na pytania dotyczące wieku menarche, aktualnego stanu zdrowia oraz statusu społeczno-ekonomicznego.

\section{Metody statystyczne}

W analizie statystycznej wykorzystano metody statystyki opisowej, test niezależności $\chi^{2}$ (dla określenia istotności różnic pomiędzy zmiennymi kategorycznymi) oraz jednoczynnikową analizę wariancji (dla określenia istotności różnic pomiędzy zmiennymi o charakterze ciągłym). Do oceny normalności rozkładów wykorzystano test W Shapiro-Wilka. Przyjęto poziom istotności p < 0,05. Wszystkie obliczenia wykonano, używając programu Statistica 10.

\section{WYNIKI}

Biorąc pod uwagę wiek pierwszej menstruacji, dokonano podziału na dziewczęta wcześnie dojrzewające (poniżej wartości 10. centyla, czyli do 11. roku życia), przeciętnie dojrzewające (11-14,5 lat) oraz późno dojrzewające (powyżej wartości 90. centyla, czyli 14,5 lat). Liczebność w poszczególnych kategoriach wynosiła kolejno: 94 (14,01\%), 510 (76,01\%) i 67 (9,99\%).

W pierwszej kolejności sprawdzono, czy wcześniejsze dojrzewanie jest związane ze statusem społeczno-ekonomicznym. Przeanalizowano czynniki takie jak: miejsce zamieszkania, liczba rodzeństwa oraz wykształcenie rodziców. Żaden z wymienionych czynników nie wpływał istotnie na zróżnicowanie tempa dojrzewania. Zaobserwowano jednak pewne tendencje. W miastach jest więcej dziewcząt wcześnie dojrzewających w stosunku do wsi. W rodzinach wielodzietnych, gdzie liczba dzieci wynosi troje lub więcej, stosunkowo niewiele jest dziewcząt wcześnie dojrzewających, najwięcej dziewcząt, u których pierwsza miesiączka wystąpiła przed 11. r.ż. zanotowano w rodzinach z dwojgiem dzieci. U córek rodziców z wykształceniem wyższym znacznie częściej notuje się wczesne wystąpienie pierwszej miesiączki. Powyższe obserwacje wskazują, że wraz ze wzrostem statusu społeczno-ekonomicznego rośnie odsetek dziewcząt wcześnie dojrzewających. Szczegółowe wyniki przedstawiono w tabeli 1.

Istotność różnic pod względem odsetka dziewcząt dojrzewających wcześnie, w normie i późno pomiędzy grupami społeczno-ekonomicznym określono za pomocą testu $\chi^{2}$.

Kolejnym analizowanym zagadnieniem było określenie zależności pomiędzy tempem dojrzewania a pomiarami i wskaźnikami antropometrycznymi. Wyniki przedstawiono w tabeli 2, natomiast $\mathrm{w}$ tabeli 3 przedstawiono częstość występowania niedoboru masy ciała oraz nadwagi i otyłości, a także otyłości brzusznej w zależności od tempa dojrzewania. U dziewcząt wcześnie dojrzewających średnie wartości BMI, obwodu pasa, WHR i WHtR są istotnie wyższe niż u dziewcząt dojrzewających przeciętnie i późno (tab. 2). Oznacza to, że wczesne dojrzewanie sprzyja występowaniu większej ilości tkanki tłuszczowej, szczególnie w okolicy centralnej. Wniosek ten potwierdzają wyniki umieszczone w tabeli 3. U dziewcząt wcześnie dojrzewających znacznie częściej występuje nadwaga i otyłość (BMI >25) oraz otyłość brzuszna (obwód pasa >80 cm).

Istotność różnic w wymiarach antropometrycznych pomiędzy dziewczętami dojrzewających wcześnie, w normie i późno określono za pomocą jednoczynnikowej analizy wariancji. Pogrubionym drukiem zaznaczono w tabelach wartości statystycznie istotne.

Istotność różnic w częstości występowania nieprawidłowej masy ciała oraz otyłości brzusznej pomiędzy dziewczętami dojrzewającymi wcześnie, w normie i późno określono za pomocą testu $\chi^{2}$. Pogrubionym drukiem zaznaczono $w$ tabelach wartości statystycznie istotne. 
TABELA 1. Tempo dojrzewania w zależności od czynników społeczno-ekonomicznych

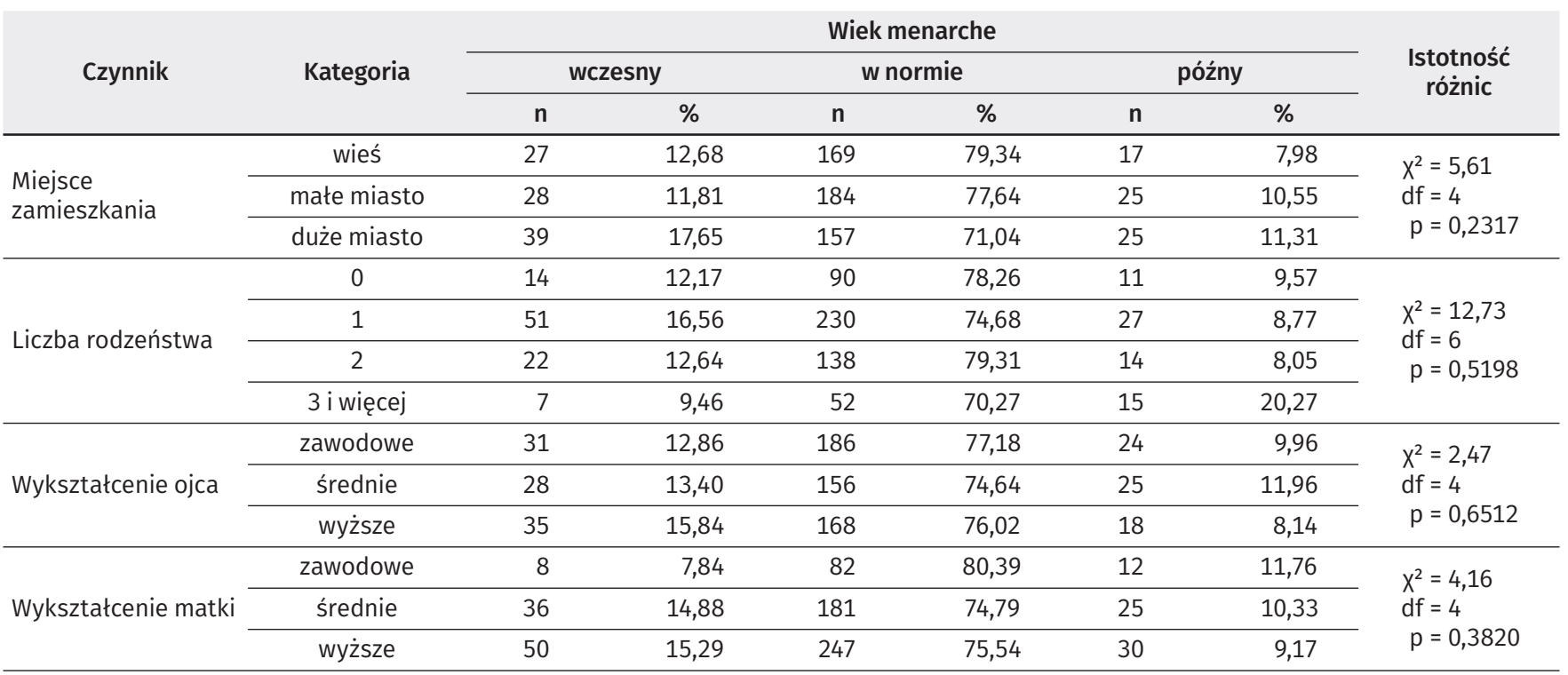

TABELA 2. Charakterystyka antropometryczna dziewcząt o różnym tempie dojrzewania

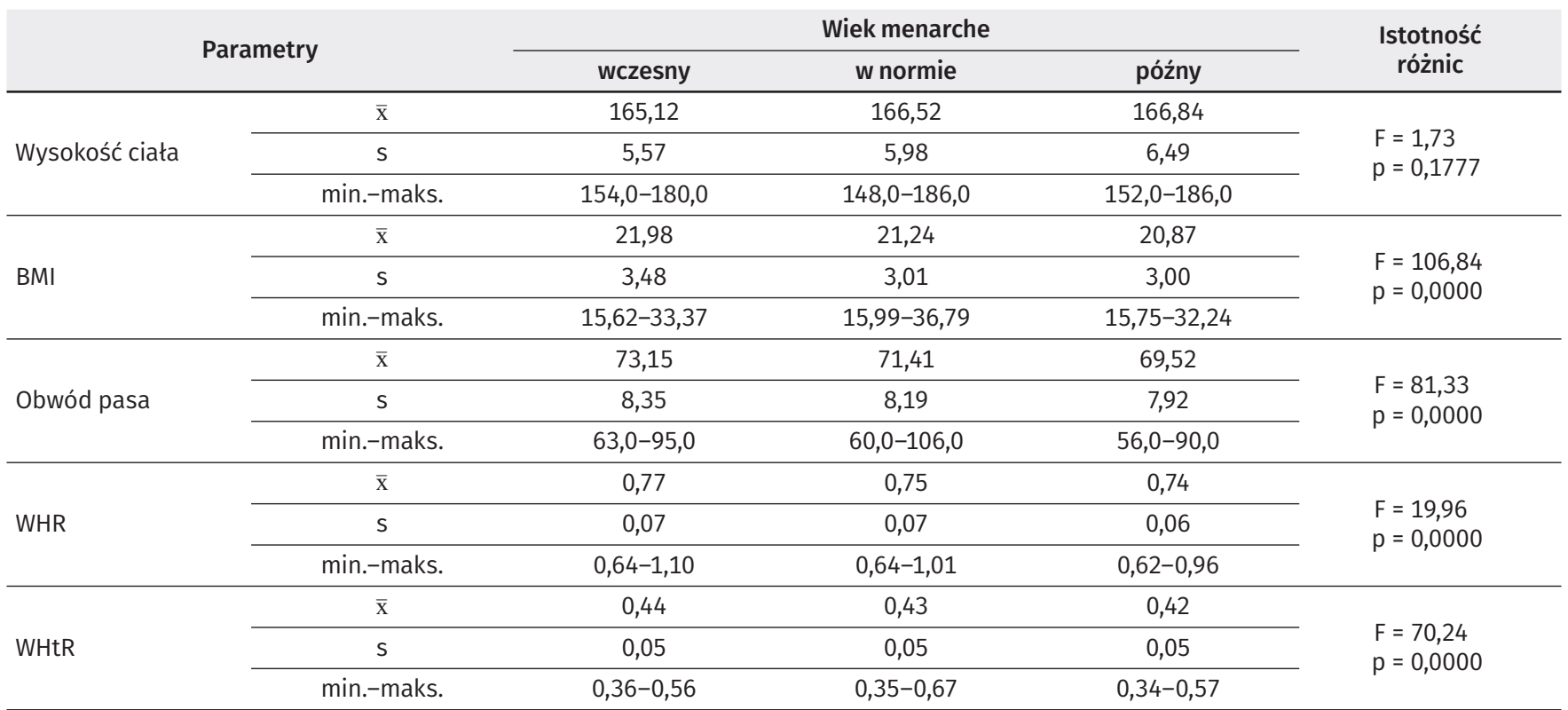

TABELA 3. Częstość występowania nieprawidłowej masy ciała oraz otyłości brzusznej w zależności od tempa dojrzewania

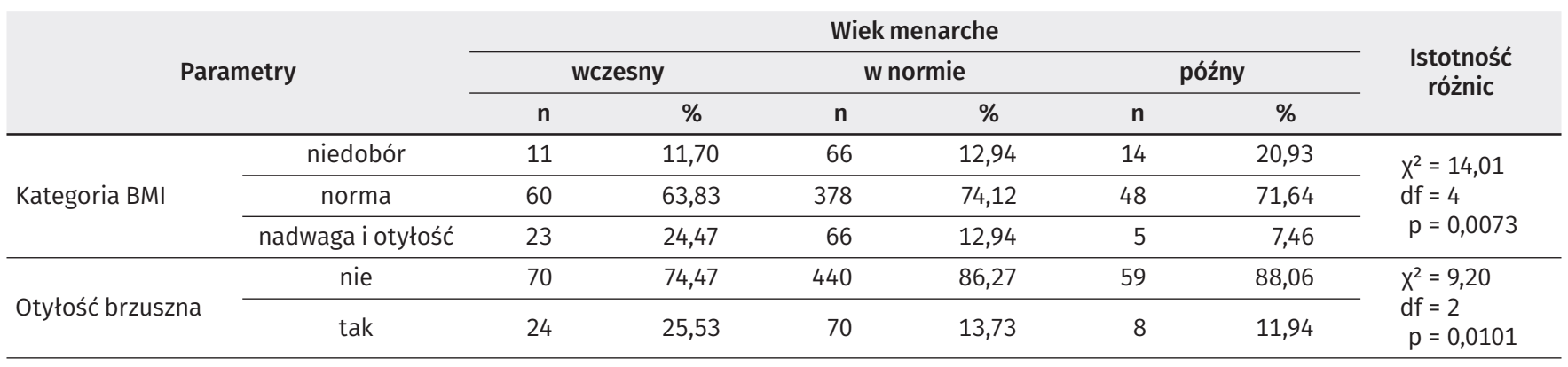

Kolejnym analizowanym problemem była zależność pomiędzy tempem dojrzewania a wybranymi elementami związanymi ze stanem zdrowia. Nie stwierdzono różnic w częstości występowania dolegliwości bólowych (bóle głowy i kręgosłupa) oraz problemów z zasypianiem w zależności od tempa dojrzewania. Analizując wyniki, nie zaobserwowano także korelacji pomiędzy wiekiem menarche a występowaniem alergii oraz częstością zapadania na choroby wirusowe (tab. 4). Można jednak zauważyć, że wśród dziewcząt wcześnie dojrzewających nieco częściej występują choroby alergiczne. 
TABELA 4. Tempo dojrzewania a czynniki wpływające na stan zdrowia

\begin{tabular}{|c|c|c|c|c|c|c|c|c|}
\hline \multirow{3}{*}{ Czynnik } & \multirow{3}{*}{ Kategoria } & \multicolumn{6}{|c|}{ Wiek menarche } & \multirow{3}{*}{ Istotność różnic } \\
\hline & & \multicolumn{2}{|c|}{ wczesny } & \multicolumn{2}{|c|}{ w normie } & \multicolumn{2}{|c|}{ późny } & \\
\hline & & $n$ & $\%$ & $n$ & $\%$ & $n$ & $\%$ & \\
\hline \multirow{3}{*}{$\begin{array}{l}\text { Choroby } \\
\text { wirusowe }\end{array}$} & kilka razy w roku & 50 & 53,19 & 271 & 53,14 & 31 & 46,27 & \multirow{3}{*}{$\begin{aligned} x^{2} & =8,31 \\
d f & =4 \\
p & =0,0808\end{aligned}$} \\
\hline & raz w roku & 19 & 20,21 & 150 & 29,41 & 18 & 26,87 & \\
\hline & rzadziej niż raz w roku & 25 & 26,60 & 89 & 17,45 & 18 & 26,87 & \\
\hline Alergie & tak & 31 & 32,98 & 145 & 28,43 & 17 & 25,38 & $\begin{aligned} x^{2} & =0,70 \\
d f & =2 \\
p & =0,7030\end{aligned}$ \\
\hline \multirow{3}{*}{ Bóle głowy } & raz w tygodniu & 17 & 18,09 & 90 & 17,65 & 10 & 14,93 & \multirow{3}{*}{$\begin{aligned} x^{2} & =3,23 \\
d f & =4 \\
p & =0,5198\end{aligned}$} \\
\hline & raz w miesiącu & 30 & 31,91 & 156 & 30,59 & 15 & 22,39 & \\
\hline & bardzo rzadko i nigdy & 47 & 50,00 & 264 & 51,76 & 42 & 62,69 & \\
\hline \multirow{3}{*}{$\begin{array}{l}\text { Bóle } \\
\text { kręgosłupa }\end{array}$} & raz w tygodniu & 16 & 17,02 & 108 & 21,18 & 14 & 20,90 & \multirow{3}{*}{$\begin{aligned} x^{2} & =9,31 \\
d f & =4 \\
p & =0,0537\end{aligned}$} \\
\hline & raz w miesiącu & 30 & 31,91 & 95 & 18,63 & 17 & 25,37 & \\
\hline & bardzo rzadko i nigdy & 48 & 51,06 & 307 & 60,20 & 36 & 53,73 & \\
\hline \multirow{2}{*}{$\begin{array}{l}\text { Problemy } \\
\text { z zasypianiem }\end{array}$} & bardzo często i często & 58 & 61,70 & 303 & 59,41 & 36 & 53,73 & \multirow{2}{*}{$\begin{aligned} x^{2} & =1,08 \\
d f & =2 \\
p & =0,5820\end{aligned}$} \\
\hline & rzadko i nigdy & 36 & 38,30 & 207 & 40,59 & 31 & 46,27 & \\
\hline
\end{tabular}

Istotność różnic w częstości występowania problemów ze zdrowiem pomiędzy dziewczętami dojrzewających wcześnie, w normie i późno określono za pomocą testu $\chi^{2}$.

\section{DYSKUSJA}

Obserwowany od wielu lat wcześniejszy wiek dojrzewania jest wynikiem wielu współdziałających ze sobą czynników zarówno genetycznych, jak i środowiskowych. Wcześniejsze osiągnięcie dojrzałości biologicznej pierwotnie rozpatrywane było jako wyłącznie pozytywny efekt, jednak obecnie liczne grono naukowców zwraca uwagę na wiele negatywnych konsekwencji [4]. W niniejszej pracy poruszono temat skutków, jakie za sobą niesie coraz to niższy wiek menarche.

Obecnie średni wiek dojrzewania w krajach Europy waha się w granicach 12-13 lat $[16,17,18]$, natomiast z początkiem XX w. pierwsza miesiączka występowała u 15-letnich dziewcząt $[18,19,20]$. Dane publikowane w literaturze naukowej świadczą o widocznej akceleracji wieku pierwszej menstruacji. Jedną z przyczyn tego trendu jest coraz wyższy status społeczno-ekonomiczny badanych, poprawa warunków i jakości życia. Pomimo że w prezentowanej pracy nie stwierdzono statystycznie istotnych różnic w tempie dojrzewania pomiędzy grupami o różnym statusie społeczno-ekonomicznym, można jednak zaobserwować tendencje do obniżania się wieku pierwszej menstruacji wraz ze wzrostem statusu. W grupach o wysokim SES więcej było dziewcząt wcześnie dojrzewających niż w grupach o statusie przeciętnym i niskim.

Tematem prac często podejmowanym przez naukowców jest zależność między tempem dojrzewania a wystąpieniem otyłości. Większy udział tkanki tłuszczowej oraz jej rozmieszczenie jest silnie skorelowane z wcześniejszym wiekiem dojrzewania. Zależność ta widoczna jest zarówno przed, jak i po okresie dojrzewania [21, 22, 23, 24]. Powszechnie wiadomo, że dziewczęta wcześnie dojrzewające charakteryzują się szybszym rozwojem i pokwitaniem niż ich rówieśniczki dojrzewające późno. Kobiety, u których pierwsza miesiączka wystąpiła późno, cechuje niższa wartość wskaźnika masy ciała. Korelacja BMI oraz tempa dojrzewania widoczna jest nawet wiele lat po okresie dojrzewania. Hulanicka i wsp. wykazali, że konsekwencje wczesnego dojrzewania i wyższych wartości wskaźnika BMI są widoczne nawet w wieku 50 lat [25]. Zaobserwowano także, iż menarche związane jest pozytywnie z obwodem pasa, a negatywnie z obwodem bioder i ud. Zależność tę reguluje m.in. leptyna stymulująca wydzielanie gonadoliberyny w podwzgórzu [26]. W badanej grupie zauważono, że studentki wcześnie dojrzewające częściej dotyka nadwaga $(24,47 \%)$ w porównaniu do studentek dojrzewających późno (7,46\%); znacznie częściej występowała też u nich otyłość brzuszna (25,53\% vs 11,94\%).

Wcześniejszy wiek pokwitania wpływa również na stan zdrowia i samopoczucie. Wyniki wielu badań wskazują, że kobiety dojrzewające późno cieszą się lepszą kondycją zdrowotną i rzadziej zapadają na choroby niż kobiety dojrzewające wcześnie [27, 28, 29].

W niniejszej pracy sprawdzano, jak tempo dojrzewania wpływa na ogólny stan zdrowia, jednak nie stwierdzono różnic w częstości występowania dolegliwości bólowych (bóle głowy i kręgosłupa), problemów z zasypianiem, zapadalnością na choroby wirusowe czy występowaniem alergii w zależności od tempa dojrzewania.

Zgodnie z opublikowanymi w literaturze naukowej pracami wczesne dojrzewanie jest silnie związane z ryzykiem wystąpienia raka piersi i nowotworów układu rozrodczego [12], zespołu metabolicznego [29], a także chorób takich jak astma [15] czy bulimia [30].

Badania nad skutkami wczesnego dojrzewania powinny być kontynuowane, gdyż stanowi ono czynnik ryzyka wielu chorób. Poznanie mechanizmu tych zależności umożliwi lepszą profilaktykę i leczenie wielu schorzeń. 


\section{WNIOSKI}

1. Nie zaobserwowano istotnych statystycznie różnic pod względem liczby osób dojrzewających wcześnie, przeciętnie i późno w zależności od czynników społeczno-ekonomicznych.

2. Dziewczęta wcześnie dojrzewające charakteryzują wyższe wartości obwodu pasa oraz BMI, WHR i WHtR niż dziewczęta dojrzewające przeciętnie i późno. Częstość występowania otyłości oraz otyłości brzusznej jest najwyższa w grupie dziewcząt wcześnie dojrzewających.

3. Analizując związek tempa dojrzewania z wybranymi elementami związanymi z ogólnym stanem zdrowia, nie stwierdzono statystycznie istotnych zależności.

\section{PIŚMIENNICTWO}

1. Kaplowitz P.: Pubertal development in girls: secular trends. Curr Opin Obstet Gynecol. 2006, 18, 487-491.

2. Kowal M., Cichocka B., Woronkowicz A., Pilecki M.W., Sobiecki J., Kryst Ł.: Międzypokoleniowe zmiany w budowie ciała i akceleracja pokwitania u dzieci i młodzieży w wieku 7-15 lat z populacji wielkomiejskiej w świetle uwarunkowań psychosocjalnych. Akad. Wychow. Fizycz. im. B. Czecha w Krakowie, Kraków 2011.

3. Parent A.S., Teilmann G., Juul A., Skakkebaek N.E., Toppari J., Bourguignon J.P.: The timing of normal puberty and the age limits of sexual precocity: variations around the world, secular trends, and changes after migration. Endocr Rev. 2003, 24, 668-693.

4. Wronka I.: Wpływ czynników społeczno-ekonomicznych na wiek menarche. In: Księga jubileuszowa. Ed. K. Kaczanowski. Wyd. Plus, Kraków 2008, 281-297.

5. McIntyre M.H.: Adult stature, body proportions and age at menarche in the United States National Health and Nutrition Survey (NHANES) III. Ann Hum Biol. 2011, 38, 716-720.

6. Okasha M., McCarron P., McEwen J., Davey Smith G.: Age at menarche, secular trends and association with adult anthropometric measures. Ann Hum Biol. 2001, 28, 68-78.

7. Malinowski A., Stolarczyk H.: Cechy budowy somatycznej dziewcząt w zależności od wieku menarche. In: Antropologia a medycyna i promocja zdrowia. Ed. A. Malinowski. Wyd. Uniw. Łódzkiego, Łódź 1996, t. 2, 258-275.

8. Wattigney W., Srinivasan S., Chen W., Greenlund K., Berenson G.: Secular trend of earlier onset of menarche with increasing obesity in black and white girls: the Bogalusa Heart Study. Ethn Dis. 1999, 9, 181-189.

9. Ribeiro J., Santos P., Duarte J., Mota J.: Association between overweight and early sexual maturation in Portuguese boys and girls. Ann Hum Biol. 2006, 33, 55-63.

10. Aksglaede L., Juul A., Olsen L.W., Srrrensen T.I.: Age at puberty and the emerging obesity epidemic. PLoS One. 2009, 4, e8450.

11. Berkey C.S., Willett W.C., Frazier A.L., Rosner B., Tamimi R.M., Colditz G.A.: Prospective study of growth and development in older girls and risk of benign breast disease in young women. Cancer. 2011, 117, 1612-1620.
12. Ahlgren M., Melbeye M., Wohlfahrt J., Thorkild I., Sorensen A.: Growth patterns and the risk of breast cancer in women. N Eng J Med. 2004, 351, 1619-1626.

13. Jacobsen B.K., Oda K., Knutsen S.F., Fraser G.E.: Age at menarche, total mortality and mortality from ischaemic heart disease and stroke: the Adventist Health Study, 1976-88. Int J Epidemiol. 2009, 38, 245-252.

14. Lakshman R., Forouhi N.G., Sharp S.J., Luben R., Bingham S.A., Khaw K.T. et al.: Early age at menarche associated with cardiovascular disease and mortality. J Clin Endocrinol Metab. 2009, 94, 4953-4960.

15. Al-Sahab B., Hamadeh, M.J., Ardern, C.I., Tamim H.: Early menarche predicts incidence of asthma in early adulthood. Am J Epidemiol. 2011, 173, 64-70.

16. Euling S.Y., Herman-Giddens M.E., Lee P.A., Selevan S.G., Juul A., Sorensen T.I. et al.: Examination of US puberty timing data from 1940 to 1994 for secular trends: panel findings. Pediatrics. 2008, 121, 172-191.

17. Rigon F., Bianchin L., Bernasconi S., Bona G., Bozzola M., Buzi F. et al.: Update on age at menarche in Italy: toward the leveling off of the secular trend. J Adolesc Health. 2010, 46, 38-44.

18. Anderson S.E., Must A.: Interpreting the continued decline in the average age at menarche: results from two nationally representative surveys of US girls studied 10 apart. J Pediatr. 2005, 147, 753-760.

19. Padez C., Rocha M.A.: Age at menarche in Coimbra (Portugal) school girls: a note on the secular hanges. Ann Hum Biol. 2003, 30, 622-632.

20. Olesen A.W., Jeune B., Boldsen J.L.: A continuous decline in menarcheal age in Denmark. Ann Hum Biol. 2000, 27, 337-348.

21. Łaska-Mierzejewska T., Olszewska E.: The maturation rate of girls living in rich and poor rural regions of Poland before and after transformation of 1989. Homo. 2004, 55, 129-142.

22. Łaska-Mierzejewska T.: Relationship between the body height/weight proportions (ponderal index) and the age at menarche. Biol Sports. 1993, 10, 245-256.

23. Buyken A.E., Karaolis-Danckert N., Remer T.: Association of prepubertal body composition in healthy girls and boys with the timing of early and late pubertal markers. Am J Clin Nutr. 2009, 89, 221-230.

24. Wronka I., Pawlińska-Chmara R.: Wpływ tempa dojrzewania na kształtowanie się dorosłych proporcji wagowo-wzrostowych u dziewcząt. Wiad Lek. 2005, 58, 513-519.

25. Hulanicka B., Lipowicz A., Kozieł S., Kowalisko A.: Relationship between early puberty and the risk of hypertension/overweight at the age 50: Evidence for modified Barker hypothesis among Polish youth. Econ Hum Biol. 2007, 5, 48-60.

26. Lassek W.D., Gaulin S.J.C.: Menarche is related to fat distribution. Am J Phys Anthropol. 2007, 133, 1147-1151.

27. Johansson T., Ritzen E.M.: Very long-term follow-up of girls with early and late menarche. Endocr Dev. 2005, 8, 126-136.

28. Peteers P.H., Verbeek A.L., Król A., Matthssien M.N., de Waard F.: Age at menarche and breast cancer risk in nulliparous women. Breast Cancer Res Treat. 1995, 33, 55-61.

29. Mueller N.T., Duncan B.B., Barreto S.M., Chor D., Bessel M., Aquino E.M. et al.: Earlier age at menarche is associated with higher diabetes risk and cardiometabolic disease risk factors in Brazilian adults: Brazilian Longitudinal Study of Adult Health (ELSA-Brasil). Cardiovasc Diabetol. 2014, 13, 22-28.

30. Kaltiala-Heino R., Rimpel M., Rissaner A., Rantaanen P.: Early puberty and early sexual activity are associated with bulimic - type eating pathology in middle adolescence. J Adolesc Health. 2001, 28, 346-352. 